Linguista: Jurnal Ilmiah Bahasa, Sastra, dan Pembelajarannya

Vol.3, No.1, Juni 2019, hal 12 - 19

ISSN (print): 2579-8944; ISSN (online): 2579-9037

Avaliable online at: http://e-journal.unipma.ac.id/index.php/linguista

\title{
Stabilitas Emosi Tokoh Sri Ningsih Dalam Novel Tentang Kamu Karya Tere Liye (Kajian Psikologi Sastra)
}

\author{
Heni Mayawati \\ MTsN Sampung Kabupaten Ponorogo, Indonesia \\ e-mail: mayawati@gmail.com
}

\begin{abstract}
Abstrak
Penelitian ini bertujuan untuk memperoleh deskripsi yang jelas tentang (1) bentuk stabilitas emosi tokoh Sri Ningsih dalam novel Tentang Kamu karya Tere Liye, dan (2) teori psikologi Abraham Maslow dalam novel Tentang Kamu. Penelitian ini menggunakan pendekatan psikologi sastra, sedangkan metode penelitian yang digunakan adalah metode deskriptif analitik. Deskriptif analitik dilakukan dengan cara pendeskripsian fakta-fakta yang kemudian disusul dengan analisis. Secara etimologi deskriptif dan analisis berarti menguraikan dengan memberikan pemahaman dan penjelasan yang secukupnya. Metode deskriptif analitik digunakan untuk memaparkan stabilitas emosi serta kondisi psikologi tokoh Sri Ningsih dengan teori psikologi Abraham Maslow. Hasil penelitian menunjukkan bahwa (1) Novel Tentang Kamu karya Tere Liye terdapat stabiltas emosi: (a) Tabah dan sabar, (b) Patuh pada orang tua, (c) Tidak mudah putus asa, (d) Mudah beradaptasi, (e) Rasa solidaritas, (f) Kreatif, (g) Inovatif, (h) Baik hati, (i) Rajin, (j) Mempunyai semangat tinggi, (k) Pekerja keras, (l) Persaudaraan, (m) Memiliki rasa percaya diri, dan (n) Bersahabat; dan (2) Ada lima hierarki kebutuhan: (a) Kebutuhan fisiologis, (b) Kebutuhan akan rasa aman, (c) Kebutuhan akan rasa memiliki dan kasih sayang, (d) Kebutuhan akan penghargaan, dan (e) Kebutuhan akan aktualisasi diri.
\end{abstract}

Kata kunci: Stabilitas emosi; Tokoh Sri Ningsih; Novel Tentang Kamu; Kajian Psikologi Sastra

\section{Emotional Stability on The Character of Sri Ningsih in The Novel "Tentang Kamu" by Tere Liye (A Literary Psychological Approach)}

\begin{abstract}
This study aims to obtain a clear description of (1) the form of emotional stability of Sri Ningsih figure in Tere Liye's novel Tentang Kamu, and (2) the psychological theory of Abraham Maslow in the novel Tentang Kamu. This study used the approach of literary psychology, while the research method used was analytical descriptive method. Descriptive analytical was done by describing facts and followed by analyzing. Etimologically, descriptive and analysis meant to elaborate by providing sufficient explanation. Descriptive analytic method was used to describe the emotional stability and psychological condition of the character of Sri Ningsih based on the psychological theory of Abraham Maslow. The results show that (1) Novel Tentang Kamu by Tere Liye contains of emotional stability: (a) Gritty and patient, (b) Obedient to parents, (c) Not easily discouraged, (d) Adaptable, (e) Sense of solidarity, (f) Creative, (g) Innovative, (h) Kindness, (i) Deligent, (j) Have high support (k) Hard worker, (I) Brotherhood feeling, ( $m$ ) Have self confidence, and (n) friendly; and (2) There are five hierarchies of needs: (a) Physiological needs, (b) Need for getting security, (c)
\end{abstract}


Need for belonging and affection, (d) Need for having reward, and (e) Need for having self-actualization.

Keywords: Skill of writing exposition text; Team Assisted Individualization

\section{Pendahuluan}

Novel merupakan salah satu bentuk karya sastra yang termasuk dalam prosa fiksi. Menurut Waluyo \& Wardani (2009: 1), prosa fiksi yaitu jenis prosa yang dihasilkan dari proses imajinasi. Imajinasi merupakan daya khayal pengarang yang dituangkan dalam cerita. Meskipun berasal dari proses imajinasi pengarang, prosa fiksi terutama novel juga terbentuk melalui pengalaman pengarang yang dituangkan dalam cerita. Jadi, pada dasarnya novel merupakan salah satu jenis prosa fiksi yang melibatkan pengalaman pengarang berdasarkan kenyataan yang ada. Pengalaman pengarang itu kemudian dituangkan ke dalam cerita dalam novel melalui tokoh-tokoh yang ada dalam novel. Selain itu, novel adalah karangan yang panjang dan mengandung rangkaian cerita kehidupan seseorang dengan orang lain di sekelilingnya dengan menonjolkan watak dan sifat setiap pelaku. Novel merupakan salah satu karya yang memadukan unsur-unsur dan peristiwa yang terjadi di kehidupan masyarakat. Hal ini ditegaskan oleh Kosasih (2012: 60) bahwa novel adalah karya imajinatif yang mengisahkan sisi utuh problematika kehidupan seseorang atau beberapa tokoh. Stanton (2007: 90) menegaskan pula bahwa novel menghadirkan perkembangan satu karakter, situasi sosial yang rumit, hubungan yang melibatkan banyak atau sedikit karakter, dan berbagai peristiwa ruwet.

Salah satu unsur penggerak jalannya cerita dalam sebuah novel adalah adanya tokoh-tokoh. Melalui tokoh-tokoh yang terdapat dalam novel, pengarang atau seniman berimaji, merefleksikan sikap, dan tingkah laku manusia di masyarakat ke dalam karya sastra. Penokohan dalam sebuah karya sastra bergantung kepada pengarang memberikan jiwa pada setiap tokoh yang ada dalam karyanya. Hal ini sesuai dengan pendapat Endraswara (2013: 87) yang mengungkapkan bahwa sastra sebagai hasil kreativitas pengarang, yang berisi tentang persoalan kehidupan, dilukiskan melalui tokoh dalam cerita. Sastra sebagai gejala kejiwaan, di dalamnya terkandung fenomenafenomena kejiwaan yang tampak lewat perilaku tokoh-tokohnya. Berdasarkan uraian sebelumnya, karya sastra yang dibahas ini, juga masih ada hubungannya dengan psikologi. Hal ini tidak lepas dari pandangan dualisme yang menyatakan bahwa manusia pada dasarnya terdiri atas jiwa dan raga. Dinyatakan oleh Paryanto (2003: 17) bahwa penelitian yang menggunakan psikologi terhadap karya sastra merupakan bentuk pemahaman atas penafsiran karya sastra dari sisi lain.

Sejalan dengan pendapat di atas, Endraswara (2008: 6) juga menyatakan bahwa karya sastra adalah fenomena kemanusiaan yang sangat kompleks. Kompleksitas ini menyebabkan karya sastra tersebut harus dikaji dengan menggunakan bantuan disiplin ilmu yang lain sebagai penunjangnya misalnya ilmu psikologi sastra. Psikologi dalam dunia sastra kini sedang berkembang, kemunculan psikologi sendiri dalam dunia sastra bukan tanpa sebab, melainkan adanya beberapa faktor. Pertama, ilmu psikologi dibutuhkan dalam sastra untuk mengkaji aspek psikologi pengarang, pembaca, serta tokoh-tokoh rekaan dalam karya sastra itu sendiri. Kedua, karena adanya unsur-unsur psikologi dalam sastra dan hubungannya dengan teori psikologi yang terkenal dengan teori hierarki kebutuhan Abraham Maslow. 
Psikologi sastra memandang bahwa karya sastra sebagai hasil kreativitas pengarang yang menggunakan media bahasa dan diabadikan untuk kepentingan estetik. Menururt Endraswara psikologi sastra adalah sebuah interdisipliner antara psikologi dan sastra (dalam Minderop, 2010: 95). Psikologi sastra adalah kajian sastra yang memandang karya sebagai aktivitas kejiwaan. Pengarang akan menggunakan cipta, rasa, dan karsa dalam berkarya. Begitu pula pembaca, dalam menanggapi karya juga tidak akan lepas dari kejiwaan masing-masing. Psikologi sastra juga mengenal karya sastra sebagai pantulan kejiwaan. Pengarang akan menangkap gejala jiwa dan dilengkapi dengan kejiwaannya kemudian diolah ke dalam teks. Proyeksi pengalaman sendiri dan pengalaman hidup di sekitar pengarang, akan terproyeksi secara imajiner ke dalam teks sastra.

Salah satu novel yang mempunyai tokoh kuat dilihat dari aspek psikologi tokoh adalah novel Tentang Kamu karya Tere Liye. Novel ini sangat menarik untuk diteliti karena dalam novel ini mengungkap tentang seorang tokoh perempuan bernama Sri Ningsih yang mengalami kisah hidup yang penuh dengan perjuangan, penuh motivasi dan patut untuk dijadikan sebagai teladan agar lebih menghargai dan mensyukuri makna dari sebuah kehidupan. Tokoh dalam novel ini digambarkan menjadi sosok yang tabah dan sabar dalam menghadapi cobaan yang terjadi dalam hidup. Kehidupan yang dialami oleh tokoh sangat rumit dan penderitaan selalu datang silih berganti. Tokoh dalam novel ini merasakan penderitaan seperti, kekerasan, ancaman, dan penderitaan batin. Kehidupan yang mendidik Sri kecil dengan keras membuatnya tumbuh dengan tangguh dan tabah. Kesabaran sang Ayah serta kekerasan hati sang lbu tiri membuatnya untuk tetap bertahan. Persahabatan yang murni menyemangatinya untuk terus berjuang.

Bentuk dari stabilitas emosi tokoh Sri Ningsih yang dilukiskan dalam wujud kepribadian sangat kuat dimunculkan oleh sang pengarang, mulai dari kepatuhannya terhadap ayah dan ibunya, kasih sayang kepada adik, dan teman-teman disekelilingnya. Perjuangan hidup yang keras membuat tokoh utama patut dijadikan teladan bagi remaja dan pelajar dalam upaya meraih suatu kesuksesan, semua itu tidak luput dari daya imajinasi pengarang yang piawai mengkomunikasikan gagasan dalam pikirannya melalui sebuah karya sastra. Dalam peranannya sebagai media komunikasi, karya sastra merupakan salah satu media yang tepat untuk menyampaikan pesan antara pengarang dengan pembacanya tentang sesuatu yang ditulis, melalui sebuah karya sastra, dialog antar pembaca dengan penulis dalam memahami maksud sebuah pesan yang terkandung dalam karya sastra diwujudkan, dalam hal ini novel.

Sebagai penulis Tere Liye memasukkan nilai-nilai pendidikan melalui tingkah laku, sikap, dan kepribadian tokoh yang ada dalam cerita. Hal ini ditujukan agar pembaca mampu memahami nilai-nilai yang terkandung dalam novel untuk diimplementasikan dalam kehidupan sehari-hari. Novel ini merupakan novel pembangun jiwa, yang mampu mendorong penikmat novel untuk tetap bersemangat dan berusaha dalam keadaan apa pun demi sebuah cita-cita yang diharapkan.

\section{Metode Penelitian}

Metode yang digunakan dalam mengkaji novel Tentang Kamu karya Tere Liye adalah metode deskriptif analitik. Menurut Ratna ( 2009: 53), deskriptif analitik dilakukan 
dengan cara pendeskripsian fakta-fakta yang kemudian disusul dengan analisis. Secara etimologi deskriptif dan analisis berarti menguraikan dengan memberikan pemahaman dan penjelasan yang secukupnya. Metode deskriptif analitik ini digunakan untuk menguraikan dan menganalisis stabilitas emosi serta kondisi psikologi tokoh Sri Ningsih dengan pendekatan psikologi Abraham Maslow pada novel Tentang Kamu karya Tere Liye.

Jenis data yang digunakan dalam penelitian ini adalah data empiris. Data empiris bersifat mendeskripsikan dan menjelaskan keadaan yang terjadi secara nyata tanpa ada rekayasa. Adapun sumber data dalam penelitian ini adalah kata, frasa, klausa, kalimat, paragraf yang terdapat dalam novel Tentang Kamu karya Tere Liye, 2016. Teknik pengumpulan data dalam penelitian ini adalah studi pustaka. Menurut Subroto (1992: 42) teknik pustaka adalah teknik yang menggunakan sumber-sumber tertulis untuk memperoleh data. Pemerolehan data dengan cara dibaca kemudian hal-hal yang penting dicatat lalu disimpulkan dan dipelajari, sumber tulisan dapat dijadikan sebagai landasan teori dan acuan dalam hubungan dengan objek yang akan diteliti.

\section{Hasil dan Pembahasan}

\section{Stabilitas Emosi Tokoh Sri Ningsih dalam Novel Tentang Kamu Karya Tere Liye.}

Dalam hidupnya manusia selalu dihadapkan pada berbagai kebutuhan, karena kebutuhan akan mendorong manusia untuk memenuhi hidupnya sehingga tercapai kepuasan. Akan tetapi dalam pemenuhan kebutuhan tersebut sering disertai adanya emosi, maka diperlukan adanya kestabilan emosi. Gerungan (1987: 138) mengatakan bahwa kestabilan emosi berarti adanya suatu kematangan berdasarkan kesadaran yang mendalam terhadap kebutuhan-kebutuhan, cita-cita dan alam perluasannya serta terintegrasi semuanya ke dalam suatu kepribadian yang pada dasarnya bulat dan harmonis. Maksudnya harmonis dalam ketegangan emosional. Keseimbangan dinamis dapat bergerak kemana dan mempunyai dasar yang matang. Pendapat senada dikemukakan oleh Albin (1995), individu yang beremosi stabil memiliki ciri-ciri kreatif, produktif, tidak mudah cemas, tidak mudah tegang serta frustasi, mandiri, mempunyai semangat yang tinggi dan efisien. Individu yang punya emosi stabil memiliki konsentrasi yang baik pada saat bekerja dan melakukan aktivitas daripada individu yang tidak memiliki kestabilan emosi.

Berdasarkan pendapat di atas, dapat disimpulkan bahwa kestabilan emosi adalah kemampuan seseorang untuk mengontrol emosinya dengan baik dalam menghadapi situasi tertentu. Sehingga seseorang dapat berpikir dan bertindak secara wajar dan tidak berlebihan dalam mengekspresikan emosi dan memperoleh keadaan yang seimbang antara psikis dan fisik walaupun dihadapkan pada tekanan hidup baik yang ringan atau yang berat.

Stabilitas emosi yang ada pada diri tokoh dalam karya sastra yang berbentuk novel merupakan hasil imajinasi dari pengarang. Stabilitas emosi ini akan memunculkan kepribadian tokoh dalam sebuah cerita. Kepribadian tokoh yang muncul memiliki ciri berbeda antar tokoh. Tokoh yang memiki stabilitas emosi biasanya akan tampak pada tokoh protagonis, kemunculan tokoh ini biasanya ditunjukkan memiliki kepribadian yang matang. Dalam novel Tentang Kamu karya 
Tere Liye pengarang berimajinasi untuk menciptakan tokoh Sri Ningsih yang kemungkinan besar hal ini juga terjadi dalam kehidupan yang sebenarnya. Dalam roda kehidupan semua bisa terjadi, orang yang miskin tapi punya kemauan yang kuat dia bisa menjadi orang yang sukses.

Tokoh yang ada dalam novel Tentang Kamu karya Tere Liye adalah tokoh yang mewakili pikiran penulis. Tokoh-tokoh itu diperhidup dengan cerita yang menyertainya. Tokoh Sri Ningsih digambarkan penulis sebagai sosok yang cerdas dan pejuang keras sehingga hal ini akan membuat kagum para pembaca. Dalam novel ini diceritakan kehidupan Sri Ningsih yang mengalami perubahan dari kehidupan seorang remaja miskin yang hidup di pulau terpencil Bungin, Sumbawa, berubah ke kehidupan di luar negeri. Dalam memperoleh kehidupan yang sukses, dia harus melaluinya dengan perjuangan yang keras, sampai akhirnya dia bisa meraih cita-citanya.

Berdasarkan pada hasil analisis, stabilitas emosi yang terdapat dalam diri tokoh Sri Ningsih tercermin pada sikap atau tindakan tokoh, yaitu tabah dan sabar, patuh pada orang tua, tidak mudah putus asa, mudah beradaptasi, rasa solidaritas, kreatif, inovatif, baik hati, rajin, mempunyai semangat tinggi, pekerja keras, persaudaraan, memiliki rasa percaya diri, dan bersahabat. Sri Ningsih adalah seorang yang tabah dan sabar dalam menghadapi pahit getir kehidupan, ini digambarkan pada wajahnya yang tetap damai dan tentram. Wajah yang selalu tabah dan berterima kasih, sampai dia meninggal wajah itu tetap sama. Sikap sabar juga tampak pada tokoh Sri yaitu menjelang usia Sri sembilan tahun. Sejak hari itu, dia sempurna menjadi yatim-piatu. Kapal Bapaknya telah tenggelam di perairan Bali. Kini dia hidup bersama ibu tirinya dan adik tirinya. Semenjak kematian bapaknya, Ibu tirinya mendadak menjadi amat benci kepada Sri, melampiaskan seluruh gusar dan marahnya pada Sri. Sri Ningsih dituntut untuk bekerja demi mencukupi seluruh kehidupan keluarganya, semua pekerjaan rumah harus dia kerjakan tanpa pernah mengeluh, itu semua dilakukan oleh Sri dengan penuh kesabaran.

Sri sejak kecil selalu patuh pada bapaknya. Dia selalu mengingat dan melakukan apa yang telah diajarkan dan diamanatkan oleh mendiang Bapaknya. la harus selalu mematuhi semua perintah ibu tirinya dan menjaga adiknya. Sikap Sri Ningsih yang tidak mudah putus asa, meskipun sudah sebulan tinggal di Jakarta Sri belum mendapatkan pekerjaan. Sri setiap hari mulai pukul tujuh pagi sampai sore menjelang malam, puluhan tempat telah didatangi untuk mencari pekerjaan, tapi tetap gagal, semua menolaknya. Tapi Sri tetap berusaha.

Sri adalah seorang yang mudah bergaul, mudah berteman dengan semua orang, dan dikenal banyak orang. Sri adalah orang yang mudah beradaptasi. Sri Ningsih adalah orang yang peduli dengan orang lain, rasa simpati terhadap orang lain dia lakukan dengan cara memberi pekerjaan anak-anak tetangganya. Sri merasa senang bisa memberikan bantuan pada orang lain.

Kreativitas yang dimiliki Sri Ningsih, yaitu dia selalu punya ide menarik. Dia telah mengubah hamparan kosong cor beton menjadi kebun yang indah dengan berbagai tanaman hidroponik. Sri Ningsih adalah orang yang pertama kali merenovasi cara berdagang kaki lima, dialah yang memulai berjualan dengan gerobak dorong seperti yang terlihat sekarang. 
Sri adalah orang yang berhati baik. Walaupun selama lima tahun terakhir dia diperlakukan buruk oleh Ibu tirinya, tapi tidak ada kebencian di mata Sri, tidak ada dendam kesumat. Sri Ningsih justru mengulurkan tangan, amat tulus hendak menolongnya. Sri Ningsih adalah anak yang rajin. Sejak tinggal di madrasah Sri rajin mengerjakan tugas termasuk yang diluar tugasnya. Dia membantu di dapur, membantu memasak, menyapu asrama, mengepel, mencuci seprai, apa pun itu. Setiap jam istirahat atau selesai sekolah, dia rajin membantu hingga larut malam, termasuk tiba-tiba ditemukan sedang sibuk menyikat seluruh kakus asrama putri malam-malam. Sikap Sri yang mempunyai semangat tinggi, meskipun usianya hampir enam puluh tahun, tapi Sri Ningsih masih mempunyai semangat untuk menjadi guru tari. Pekerjaan menjadi guru tari telah membawanya berkeliling dunia. Sri Ningsih adalah orang yang pekerja keras, mempunyai semangat yang menggebu-gebu dalam usahanya sampai dia berhasil menjadikan pabrik perusahaan sabun 'Rahayu' laris manis dan telah menguasai pasar.

Sikap Sri Ningsih yang selalu peduli pada orang lain yang membutuhkan. Dia menolong Chaterine yang hidup di jalanan dijadikannya sebagai saudara, diberinya tempat tinggal, makan, mendidiknya, dan memberikannya pekerjaan. Dia memiliki jiwa persaudaraan. Sri Ningsih adalah orang yang memiliki rasa percaya diri, saat Sri mulai menghadapi satu demi satu masalah serius pada usahanya, dia percaya semua akan bisa dia selesaikan dengan segala potensi yang ia miliki. Dia mulai berpikir untuk menemukan ide-ide baru, peluang-peluang berbeda, agar bisnisnya terus berjalan. Dia selalu siap untuk memulai sesuatu yang berbeda, bersiap dengan terobosan baru. Sri adalah orang yang periang, aktif, humoris, membawa semangat baru bagi orang-orang yang ada disekitarnya. Dia memiliki jiwa yang bersahabat.

\section{Teori Psikologi Satra Abraham Maslow dalam Novel Tentang Kamu karya Tere}

Liye.

Menurut aspek psikologi tokoh yang dikemukakan oleh Abraham Maslow ada lima hierarki kebutuhan yang sebenarnya ingin dipenuhi oleh setiap manusia. Pada dasarnya lima kebutuhan itu, yaitu: (a) kebutuhan fisiologis; (b) kebutuhan akan rasa aman; (c) kebutuhan akan rasa memiliki dan kasih sayang; (d) kebutuhan akan penghargaan, dan; (e) kebutuhan akan aktualisasi diri. Dari kelima hierarki kebutuhan tersebut harus dipenuhi dari yang paling bawah baru menuju pada kebutuhan diatasnya. Kebutuhan aktualisasi diri akan terpenuhi ketika keempat kebutuhan dibawahnya dapat terpenuhi.

Ketika manusia ingin bertahan hidup maka, dia harus mampu mencukupi kebutuhan fisiologis. Karena kebutuhan fisiologis sangat mendasar dan bersifat mutlak bagi manusia. Kebutuhan fisiologis itu seperti, makan, minum, tempat berteduh, tidur, dan oksigen. Jika kebutuhan fisiologis tidak dapat terpenuhi maka akan berpengaruh pada kelangsungan hidup manusia. Dalam memenuhi kebutuhan makanan Sri kecil harus bekerja keras dari pagi sampai petang agar dapat memperoleh uang untuk membeli beras. Dalam hal ini, Sri harus berpikir bagaimana cara mendapatkan makanan. Demikian juga dalam memenuhi kebutuhan minum dia harus menyebrang ke pulau untuk mendapatkan air bersih. 
Setelah kebutuhan fisiologis terpenuhi, muncul kebutuhan yang berada diatasnya, yakni kebutuhan akan rasa aman. Kebutuhan akan rasa aman ini sebenarnya kunci bagi manusia untuk melangsungkan hidup dan mencapai kebahagiaan. Kebutuhan ini muncul ketika Bapak Sri meninggal dan Sri hidup bersama ibu tirinya. Sri mengalami kekerasan baik fisik maupun batin. Setiap hari Sri merasakan kecemasan dan ketakutan akan kemarahan dari ibunya. Setelah peristiwa malam itu, rumah beserta ibu tirinya terbakar. Akhirnya Sri mendapatkan keluarga baru, tetangga baru, dan sahabat baru setelah tinggal di madrasah Kiai Ma'sum. Keluarga yang peduli pada dirinya.

Kebutuhan akan rasa memiliki dan kasih sayang juga merupakan kebutuhan yang ingin dicapai oleh setiap manusia. Seseorang menginginkan disayangi dan menyayangi orang yang ada disekitarnya. Rasa ingin disayangi dan dicintai ada pada hati setiap manusia. Pada awalnya Sri adalah orang yang tidak peduli pada pasangan hidup, dia berpikir tidak akan ada laki-laki yang mau dengannya karena bentuk fisiknya yang jelek. Tapi pada akhirnya Sri menemukan orang yang betulbetul tulus mencintainya. Bukan karena bentuk fisik tapi karena kebaikan hati seorang Sri Ningsih.

Kebutuhan akan penghargaan adalah kebutuhan seseorang untuk mendapatkan rasa dihormati, dihargai, dan dianggap penting bagi setiap orang yang berhubungan dengan dirinya. Kebutuhan akan penghargaan pada dasarnya dapat dicapai ketika seseorang mampu mendapatkan kesuksesan. Kesuksesan itu dapat berupa pendidikan, status, prestasi, kedudukan seseorang, ataupun dengan materi. Sri Ningsih yang dulunya hanya seorang anak yang miskin dengan semangat dan kerja kerasnya akhirnya dia menjadi seorang yang sukses. Dia juga seorang yang memiliki jiwa bersahabat, berhati baik, sehingga selalu dihargai keberadaannya oleh orang lain.

Kebutuhan terakhir yang ingin dicapai oleh setiap manusia adalah kebutuhan aktualisasi diri, yakni kebutuhan untuk mengekspresikan kemampuan yang dimiliki setelah keempat kebutuhan lainnya terpenuhi. Sri Ningsih adalah orang yang berbakat dalam berbagai hal, dia selalu punya ide-ide brilian, dengan kemampuan yang dimilikinya terus dia kembangkan, pekerja keras, pantang menyerah oleh keadaan, akhirnya dia menjadi orang yang sukses.

\section{Kesimpulan}

Berdasarkan temuan yang didapatkan kesimpulan bahwa stabilitas emosi serta kondisi psikologi tokoh Sri Ningsih dalam novel Tentang Kamu karya Tere Liye sebagai berikut: Pertama, pada hakikatnya stabilitas emosi adalah kemampuan seseorang untuk mengontrol emosinya dengan baik dalam menghadapi situasi tertentu. Sehingga seseorang dapat berpikir dan bertindak secara wajar dan tidak berlebihan dalam mengekspresikan emosi dan memperoleh keadaan yang seimbang antara psikis dan fisik walaupun dihadapkan pada tekanan hidup baik yang ringan atau yang berat. Dalam novel Tentang Kamu karya Tere Liye dapat ditemukan empat belas stabilitas emosi yang terdapat pada diri tokoh Sri Ningsih yang tercermin dalam sikap atau tindakan tokoh, yaitu tabah dan sabar, patuh pada orang tua, tidak mudah putus asa, mudah beradaptasi, rasa solidaritas, kreatif, inovatif, baik hati, rajin, mempunyai semangat 
tinggi, pekerja keras, persaudaraan, memiliki rasa percaya diri, dan bersahabat. Kedua, kondisi psikologi tokoh Sri Ningsih ini dianalisis dengan teori hierarki kebutuhan Abraham Maslow. Menurut aspek psikologi tokoh yang dikemukakan oleh Abraham Maslow ada lima hierarki kebutuhan yang sebenarnya ingin dipenuhi oleh setiap manusia. Pada dasarnya lima kebutuhan itu, yaitu: (a) kebutuhan fisiologis; (b) kebutuhan akan rasa aman; (c) kebutuhan akan rasa memiliki dan kasih sayang; (d) kebutuhan akan penghargaan, dan; (e) kebutuhan akan aktualisasi diri. Dari kelima hierarki kebutuhan tersebut harus dipenuhi dari yang paling bawah baru menuju pada kebutuhan diatasnya. Kebutuhan aktualisasi diri akan terpenuhi ketika keempat kebutuhan di bawahnya dapat terpenuhi.

\section{Daftar Pustaka}

Albin, R.S. (1995). Emosi Bagaimana Mengenal, Menerima, dan Mengarahkannya. (Terjemahan: S.M. Brigid, O.S.F). Yogyakarta: Kanisius.

Endraswara, S. (2008). Metodologi Penelitian Sastra: Epistemologi, Model, Teori, dan Aplikasi. Yogyakarta: Media Presindo.

Endraswara, S. (2013). Metodologi Penelitian Sastra. Yogyakarta: CAPS.

Gerungan, G. (1987). Psikologi Sosial. Bandung: Ereslo

Kosasih, E. (2012). Dasar-dasar Keterampilan Bersastra. Bandung: Yrama Widya.

Liye, T. (2017). Tentang Kamu. Jakarta: Republika.

Minderop, A. (2010). Psikologi Sastra: Karya Sastra, Metode, Teori, dan Contoh Kasus. Jakarta: Yayasan Pustaka Obor Indonesia.

Paryanto, A. (2003). Aspek Moral dalam Novel Para Priyayi Analisis Psikologi Sastra. Surakarta: Universitas Muhamadiyah Surakarta.

Ratna, N.K. (2009). Teori, Metode, dan Teknik Penelitian Sastra. Yogyakarta: Pustaka Pelajar.

Stanton, R. (2007). Teori Fiksi Robert Stanton (Diterjemahkan oleh Sugihastuti dan Rossi Abi Al Irsyad). Yogyakarta: Pustaka Pelajar.

Subroto, E. (1992). Pengantar Metode Penelitian Linguistik Struktural. Surakarta: UNS Press

Waluyo, H. J. dan Wardani, N. E. (2009). Pengkajian dan Apresiasi Prosa Fiksi. Surakarta: Universitas Sebelas Maret. 